\title{
Plate Heat Exchangers as a Compact Design and Optimization of Different Channel Angles
}

\author{
M. KAN*, O. IPEK AND B. GUREL \\ Mechanical Engineering, Isparta, Turkey
}

\begin{abstract}
In this study, thermal treatments have been investigated for different channel angles and mass flow rates of a compact heat exchanger have been manufactured by direct metal laser sintering technique instead of a sealed and brazed one used in many areas. Boundary conditions of available heat exchanger experimental test have been used in laboratory. In this study, we have designed for compact heat exchanger of $30^{\circ}, 45^{\circ}$ and $60^{\circ}$ channel angle and used three different mass flow rates $(0.2,0.3$, and $0.43 \mathrm{~kg} / \mathrm{s})$. Heat transfers occurring between heat channels and walls of heat exchangers for different channel angles and efficiency of heat exchangers have been calculated. As a result of the analysis, it has been determined that in order for maximum of heat transfer of a compact heat exchanger, following working conditions ought to be fulfilled: channel angle $30^{\circ}$, hot water input temperature $60^{\circ} \mathrm{C}$, cold water input temperature $15^{\circ} \mathrm{C}$, and mass flow rate $0.43 \mathrm{~kg} / \mathrm{s}$.
\end{abstract}

DOI: 10.12693/APhysPolA.128.B-49

PACS: $44.15 .+\mathrm{a}$

\section{Introduction}

To improve heat transfer in flow channels, the numerical and experimental studies were mentioned in some specific papers. Reppich and Kohoutek [1] reported that lower flow rate and the flow channel between the hot plates under high turbulence conditions of heat exchangers are characterized which were broadly used in chemical and other industrial applications. Hopkinson and Dickens [2] investigated direct metal laser melting system by using this method of heat transfer in different heating and cooling channel geometry of the experimental material, which is made by bronze. The correlations of heat transfer and temperature distribution in the channel was derived. Gut and Pinto [3] developed the generalized mathematical model of a gasketed plate heat changers using an algorithmic form. Franco and Giannini [4] analysed plate-fin heat exchangers using analysis of counter-flow heat exchangers and compact heat exchangers. Erek et al. [5] numerically studied the effect of changing pressure drop and heat transfer in geometry of blade in the plate finned tube heat exchanger. Durmus et al. [6] experimentally investigated the heat transfer plates for three different surface geometry, friction factor and energy losses. Dovic et al. [7] also researched the flow characteristics of the chevron type heat exchanger as the plate surface angle $\beta=28^{\circ}$ and $\beta=61^{\circ}$, respectively and derived new fanning friction factor and the Nusselt number for flow plate channels to estimate for use in correlations. Yildirim and Guo [8] investigated the structures of the micro-channel heat exchangers and analysed fluid thermal performance. They derived correlations of temperature distribution and heat exchanger

*corresponding author; e-mail: mehmetkan@sdu.edu.tr efficiency. Gherasim et al. [9] experimentally studied two-channel chevron type plate heat exchanger in the hydrodynamic and thermal fields for laminar and turbulent flow conditions. Mancini et al. [10] experimentally studied the effects of the superheating on brazed plate exchanger prototypes in $\mathrm{R} 407 \mathrm{C}$ and $\mathrm{R} 410 \mathrm{~A}$ refrigerants at different geometric feature and aspect ratio of plate design. Faizal and Ahmed [11] made an experimental study on temperature difference of the heat exchangers of the plates used in small applications. Kılıc [12] studied thermal and dynamic parameters at three different geometry channels $\left(30^{\circ}, 45^{\circ}\right.$ and $60^{\circ}$ channel angles) in the gasketed plate heat exchanger and also examined the effect of the thermal and dynamic parameters at different geometry channels.

$3 \mathrm{D}$ designs of heat exchanger in a compact standard sized channel angle of $30^{\circ}, 45^{\circ}$ and $60^{\circ}$ have been drawn in this study. According to the design of three different boundary conditions, by using the ANSYS-FLUENT software, input, output and channel flow and thermal behaviour of the flow of water circulating in the system were investigated.

\section{Numerical modelling}

Heat exchanger geometric properties and process parameters are given in Table I. This heat exchanger 3D CAD model is shown in Fig. 1.

Mesh structure is formed by 10,000,000 tetrahedral meshes. Finite volume grid structure for heat exchanger of designing with 3D CAD software executed with tetrahedral mesh software. In Fig. 2 there are observed plate heat exchanger mesh structures of $30^{\circ}, 45^{\circ}, 60^{\circ}$ plate channel angles.

\subsection{Boundary conditions}

In this study, three different channel angels of manufacturing DMLS method compact heat exchangers have 


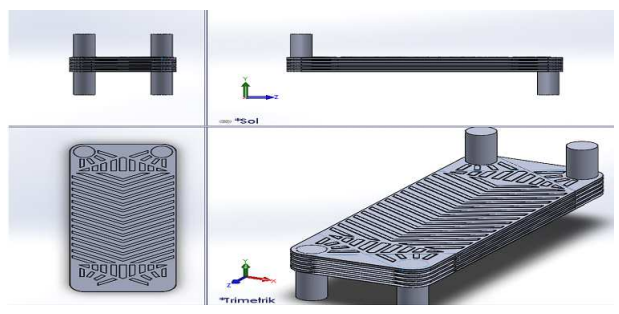

Fig. 1. Solid model of the heat exchanger.

TABLE I

The geometric properties of the heat exchanger and process parameters.

\begin{tabular}{l|l}
\hline \hline the length of the compact heat exchanger & $192 \mathrm{~mm}$ \\
the width of the compact heat exchanger & $74 \mathrm{~mm}$ \\
number of plates & 10 \\
hot water inlet temperature & $60^{\circ} \mathrm{C}$ \\
cold water inlet temperature & $15^{\circ} \mathrm{C}$ \\
environment temperature & $27^{\circ} \mathrm{C}$ \\
channel angles & $30^{\circ}, 45^{\circ}, 60^{\circ}$ \\
hot water and cold water flow rate & $0.2,0.3,0.43 \mathrm{~kg} / \mathrm{s}$
\end{tabular}

been designed by authors. These designs were referred to by brazed plate heat exchanger dimensions. Brazed plate heat exchanger dimensions are shown in Table I. In this study we have done analysis for $30^{\circ}, 45^{\circ}$ and $60^{\circ}$ channel angles compact plate heat exchanger. Mass flow rates are given by $0.2,0.3$, and $0.43 \mathrm{~kg} / \mathrm{s}$, hot water input temperature is given by $60^{\circ} \mathrm{C}$, cold water input temperature is given by $15^{\circ} \mathrm{C}$ (Fig. 3) and ambient temperature is given by $27^{\circ} \mathrm{C}$.

\subsection{Numerical modeling}

In this study there is used ANSYS-FLUENT 14 software based on finite volume method and the following equations [13].

Continuity equation

$$
\frac{\partial u}{\partial x}+\frac{\partial v}{\partial y}+\frac{\partial w}{\partial z}=0
$$

Conservation of momentum equation

$$
\begin{aligned}
& \frac{\partial}{\partial t}(\rho \boldsymbol{V})+\nabla \cdot((\rho \boldsymbol{V}) \boldsymbol{V})= \\
& \quad-\nabla p+\nabla \cdot(\overline{\bar{T}})+\rho \boldsymbol{g}+\boldsymbol{F}
\end{aligned}
$$

is shaped, where $p$ is the static pressure, $T$ - stress tensor, $g$ is the gravitational acceleration, $F$ can be given by the user of the term referring to other sources [13].

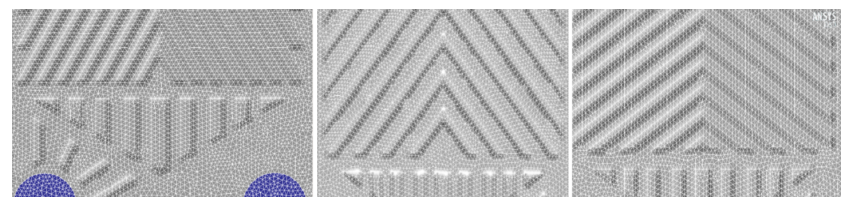

Fig. 2. Plate heat exchanger mesh structures of $30^{\circ}$, $45^{\circ}, 60^{\circ}$ plate channel angles.

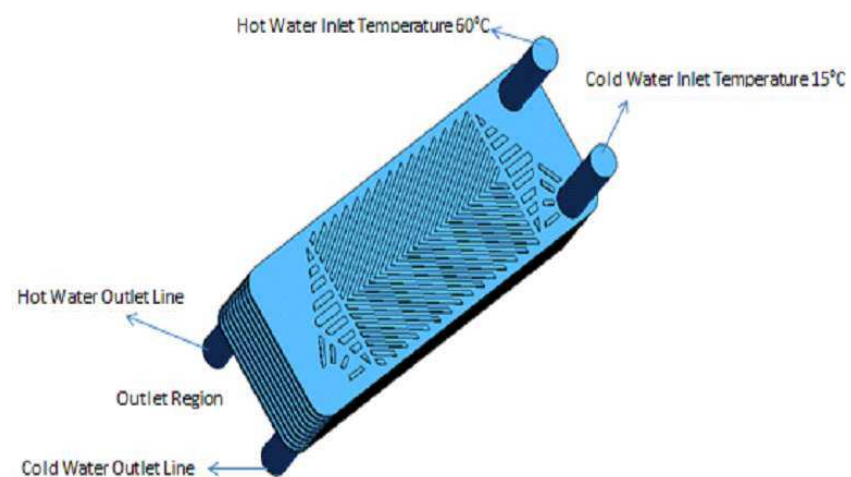

Fig. 3. Compact heat exchanger design.

Energy equation

$$
\begin{aligned}
& \frac{\partial(\rho E)}{\partial t}+\nabla \cdot(\boldsymbol{V}(\rho E+p))= \\
& \nabla\left[k_{\mathrm{eff}} \nabla T-\sum_{j} h_{i} J_{i}+\left(\overline{\bar{T}}_{\mathrm{eff}} \cdot \boldsymbol{V}\right)\right]+S_{h}
\end{aligned}
$$

is shown in.

In this equation $E-$ unit of energy, $k_{\text {eff }} \nabla T$ - transmission, $\sum_{j} h_{i} J_{i}$ - diffusion and $\left(\overline{\bar{T}}_{\mathrm{eff}} \boldsymbol{V}\right)-$ viscous energy loss (disposition) is represented from [13].

Equations modeling parameters of numerical solutions are given in Table II.

TABLE II

Numerical modeling parameters used solution.

\begin{tabular}{l|l}
\hline \hline simulation condition & steady-state \\
solver type & pressure based \\
mesh structure/mesh number & tetrahedral/10 million \\
turbulence model & standard k- $\varepsilon$ turbulence model \\
wall-turbulence interaction & standard wall-function \\
pressure--velocity coupling & SIMPLE algorithm \\
discretization method & second order upwind
\end{tabular}

Total heat transfer for heat exchanger can be written by the following equations $[4,5]$ :

$$
\begin{aligned}
& Q=K A \Delta t_{\mathrm{m}}, \\
& Q=\dot{m}_{\mathrm{h}} c_{\mathrm{ph}}\left(t_{\mathrm{hg}}-t_{\mathrm{h}}\right)=\dot{m}_{\mathrm{c}} c_{\mathrm{pc}}\left(t_{\mathrm{c}}-t_{\mathrm{cg}}\right),
\end{aligned}
$$

where $\dot{m}_{\mathrm{h}}$ and $\dot{m}_{\mathrm{c}}$ - mass flow rate of hot and cold fluids, respectively $(\mathrm{kg} / \mathrm{s}), c_{\mathrm{ph}}$ and $c_{\mathrm{pc}}$ - specific heat of the hot and cold fluids, respectively $(\mathrm{J} /(\mathrm{kg} \mathrm{K})), t_{\mathrm{hg}}$ and $t_{\mathrm{h}}$ inlet and outlet hot fluid temperatures, respectively $\left({ }^{\circ} \mathrm{C}\right)$, $t_{\mathrm{cg}}$ and $t_{\mathrm{c}}$ - inlet and outlet cold fluid temperatures, respectively $\left({ }^{\circ} \mathrm{C}\right)$.

Equation often used in the form of dimensionless equations of fluid flow in or out of different geometries [14]:

$\operatorname{Re}=w D / v$.

The effectiveness of the heat exchanger is calculated using the following equation [14]:

$$
\varepsilon=Q / Q_{\max } .
$$




\section{Results}

As shown in Table III, hot water outlet temperature, cold water outlet temperature, amount of heat transfer, effectiveness, and Reynolds number change with different channel angles $\left(30^{\circ}, 45^{\circ}\right.$, and $\left.60^{\circ}\right)$ and different mass flow rates $(0.2,0.3$, and $0.43 \mathrm{~kg} / \mathrm{s})$.

TABLE III

Changing analyses results for different channel angles and different mass flow rates.

\begin{tabular}{|c|c|c|c|c|c|c|c|c|c|}
\hline 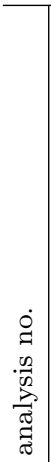 & 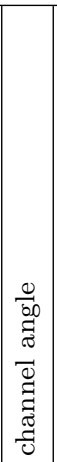 & 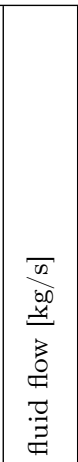 & 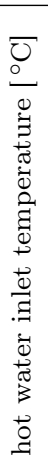 & 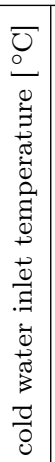 & 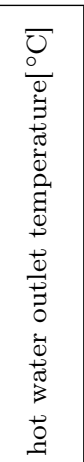 & 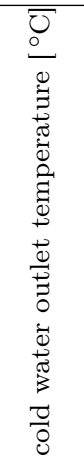 & 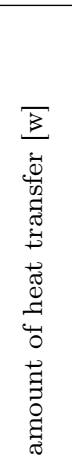 & 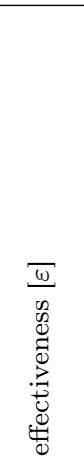 & 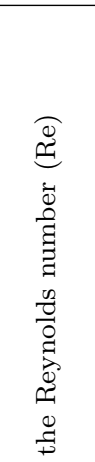 \\
\hline 1 & 30 & 0.2 & 60 & 15 & 52.28 & 22.88 & 6454 & 0.171 & 6020 \\
\hline 2 & 45 & 0.2 & 60 & 15 & 51.69 & 22.79 & 6947 & 0.185 & 5862 \\
\hline 3 & 60 & 0.2 & 60 & 15 & 51.59 & 23.51 & 7031 & 0.187 & 5937 \\
\hline 4 & 30 & 0.3 & 60 & 15 & 53.89 & 21.53 & 7662 & 0.135 & 9027 \\
\hline 5 & 45 & 0.3 & 60 & 15 & 53.78 & 21.23 & 7800 & 0.138 & 8851 \\
\hline 6 & 60 & 0.3 & 60 & 15 & 53.63 & 21.75 & 7988 & 0.141 & 8980 \\
\hline 7 & 30 & 0.43 & 60 & 15 & 54.67 & 20.44 & 9580 & 0.118 & 13084 \\
\hline 8 & 45 & 0.43 & 60 & 15 & 54.7 & 20.75 & 9526 & 0.117 & 12761 \\
\hline 9 & 60 & 0.43 & 60 & 15 & 54.82 & 18.66 & 9310 & 0.115 & 12955 \\
\hline
\end{tabular}

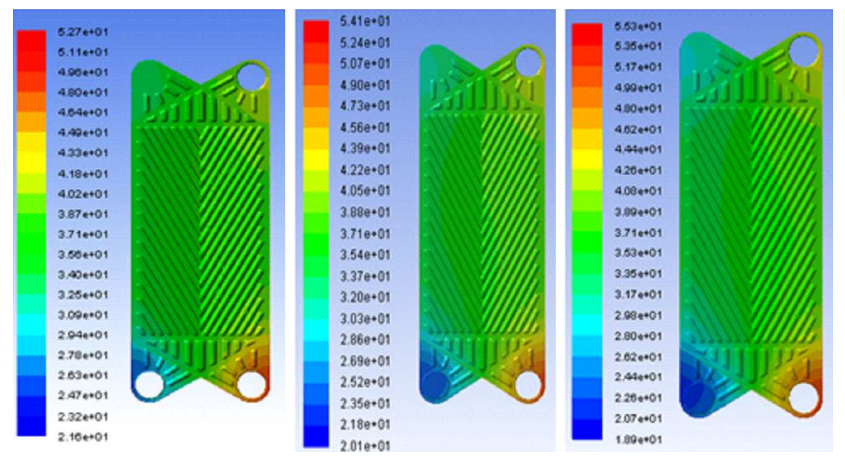

Fig. 4. Changing of Temperatures for Different mass flow rate in the $30^{\circ}$ angle heat exchanger.

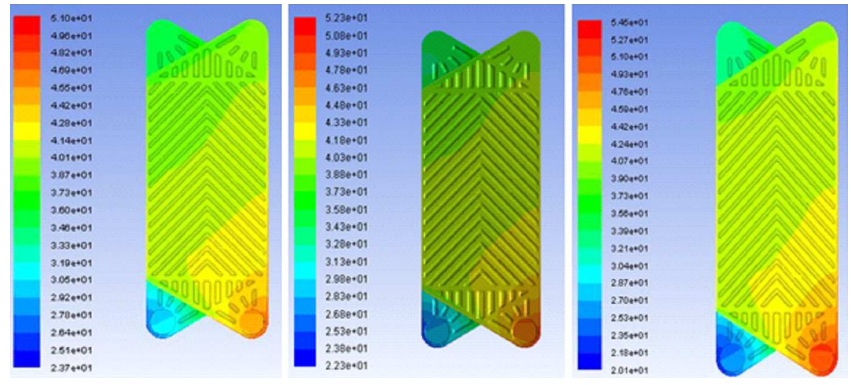

Fig. 5. As in Fig. 4, but for $45^{\circ}$ angle.

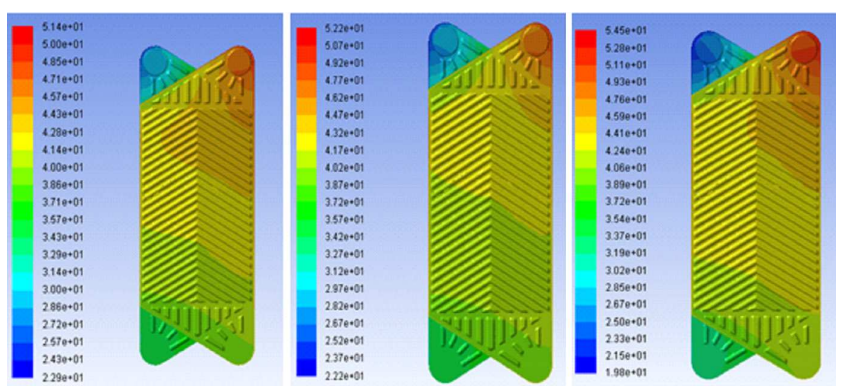

Fig. 6. As in Fig. 4, but for $60^{\circ}$ angle.
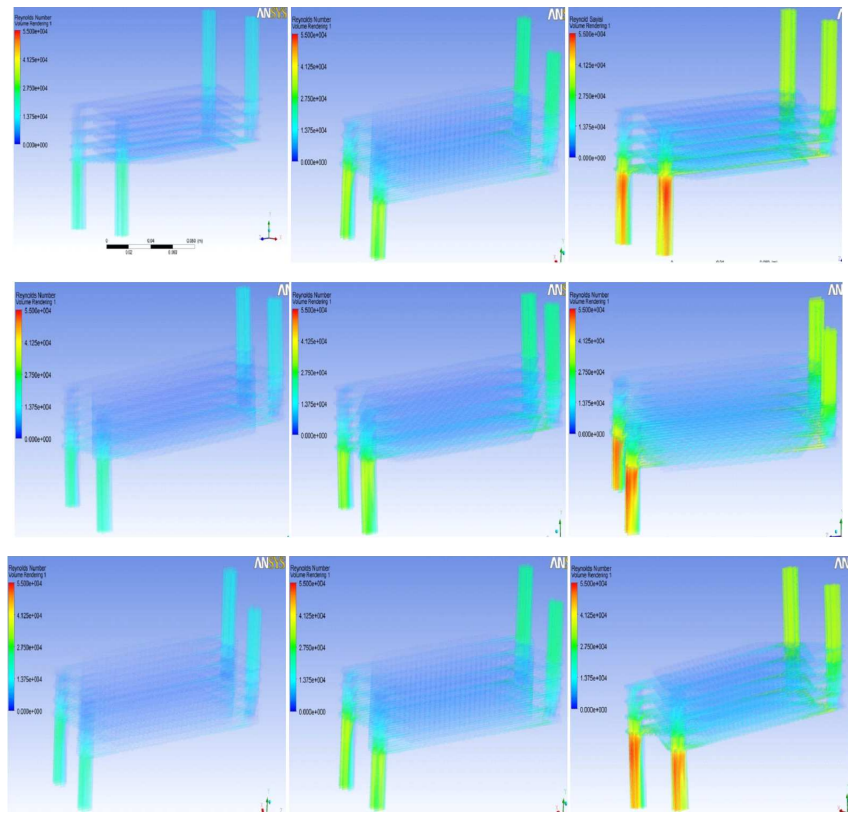

Fig. 7. Changing of Reynolds number for different mass flow rate in the angle heat exchanger of $30^{\circ}$ (top), $45^{\circ}$ (middle), $60^{\circ}$ (bottom).

As could be seen in Table III, when the mass flow rates and channel angles are increased, the amount of heat transfer and Reynolds number are increased but effectiveness of heat exchanger is decreased.

As shown in Figs. 4-6, respectively, $30^{\circ}-45^{\circ}-60^{\circ}$ angle for the $0.2,0.3$, and $0.43 \mathrm{~kg} / \mathrm{s}$ mass flow rate in the heat exchanger temperature change. As can be seen in Fig. 6, $0.2 \mathrm{~kg} / \mathrm{s}$ and $30^{\circ}$ channel angle is the best effectiveness in terms of process parameters and channel angle.

As shown in Fig. 7 , respectively, $30^{\circ}-45^{\circ}-60^{\circ}$ angle for the $0.2,0.3$, and $0.43 \mathrm{~kg} / \mathrm{s}$ mass flow rate in the heat exchanger temperature change. As can be seen in Fig. 6, $0.43 \mathrm{~kg} / \mathrm{s}$ and $30^{\circ}$ channel angle are the best values for the Reynolds number in terms of process parameters and channel angle.

\section{Conclusions}

According to the obtained results, the increase in mass flow rate leads to increase in the heat transfer rate. However, the mass flow rate is low, cold water outlet temperature and the hot water outlet temperature values showed 
no further change. In future studies, the specific application used in micro-scale heat exchanger design can be made taking into consideration the results of the study. Micro-sized heat exchangers were designed with direct metal laser sintering (DMLS) method that can manufacture one piece. This heat exchanger that would have been manufactured by DMLS method can be done by experimental tests in heat exchanger. As a result, importance of the numerical analysis for the compact plate heat exchanger in the manufacture, design and optimization stage has emerged.

\section{References}

[1] M. Reppich, J. Kohoutek, Chem. Eng. Proc. 18, 295 (1994).

[2] N. Hopkinson, P. Dickens, J. Eng. Manufact. 214, 891 (2000).

[3] J.A.W. Gut, J.M. Pinto, Int. J. Heat Mass Transf. 47, 4833 (2004).

[4] A. Franco, N. Giannini, Appl. Therm. Eng. 25, 1293 (2004).

[5] A. Erek, B. Özerdem, L. Bilir, Z. İlken, Appl. Therm. Eng. 25, 2421 (2005).
[6] A. Durmus, H. Benli, I. Kurtbas, H. Gul, Int. J. Heat Mass Transf. 52, 1451 (2009).

[7] D. Dovic, B. Palm, S. Svaic, Int. J. Heat Mass Transf. 52, 4553 (2009).

[8] O. Yildirim, Z. Guo, "High-efficiency Micro Channel Regenerative Heat Exchanger for Fluid Processing", in: Comsol User Conf., 2011..

[9] I. Gherasim, M. Taws, N. Galanis, C.T. Nguyen, Int. J. Therm. Sci. 50, 1492 (2011).

[10] S. Mancin, D.D. Col, L. Rossetto, Exp. Therm. Fluid Sci. 36, 149 (2012).

[11] M. Faizal, M.R. Ahmed, Exp. Therm. Fluid Sci. 36 , 242 (2012).

[12] B. Kılıç, Ph.D. Thesis, Suleyman Demirel University Natural and Science Institution, Isparta 2013, p. 50.

[13] Fluent, Version 14.0 User's Guide, Fluent Inc., Lebanon (NH) 2013.

[14] W.M. Kays, A.L. London, E.R.G. Eckert, Compact Heat Exchangers, Krieger Publ. Co., Malabar, Florida 1960. 